\title{
KONDISI PERAIRAN SUNGAI MOROSARI DEMAK PADA LOKASI YANG BERBEDA DITINJAU DARI KANDUNGAN KLOROFIL-a, NITRAT, FOSFAT, DAN FITOPLANKTON
}

\author{
Water Conditions of Morosari River Demak at Different Locations in Terms \\ of Chlorophyll-a, Nitrate, Phosphate contents, and Phytoplankton
}

\section{Rina Mariana, Siti Rudiyanti, Boedi Hendrarto}

\author{
Program Studi Manajemen Sumberdaya Perairan, Departemen Sumberdaya Akuatik \\ Fakultas Perikanan dan Ilmu Kelautan, Universitas Diponegoro \\ J1. Prof. Soedarto, SH, Tembalang, Semarang, Jawa Tengah - 50275, Telp/Fax. +6224 7474698 \\ Email : rinamarianamsp10@gmail.com
}

\begin{abstract}
ABSTRAK
Sungai Morosari berada di Kecamatan Sayung, Kabupaten Demak. Perairan ini digunakan untuk pembuangan limbah domestik maupun industri, jalur lalu lintas perahu nelayan, kawasan wisata, dan kegiatan perikanan. Hal ini diduga mempengaruhi kualitas perairan. Penelitian dilakukan pada bulan April-Mei 2014, bertujuan untuk mengetahui kondisi perairan Sungai Morosari berdasarkan kandungan klorofil-a, nitrat, fosfat, dan struktur komunitas fitoplankton. Variabel pendukung penelitian antara lain temperatur, arus, kedalaman, kecerahan, pH, salinitas, dan oksigen terlarut. Pengambilan sampel pada penelitian ini ditentukan empat stasiun dengan tiga kali pengulangan. Analisis data yang digunakan untuk menggunakan analisis kluster dan analisis non parametrik Kruskal-Wallis. Hasil penelitian menunjukkan terdapat perbedaan yang nyata pada kandungan klorofil-a dan fosfat tiap stasiun, sedangkan pada kandungan nitrat tidak terdapat perbedaan yang nyata. Kemiripan tertinggi berdasarkan komunitas fitoplankton terletak pada daerah yang didominasi pemukiman penduduk dan daerah lalu lintas perahu nelayan, sedangkan kemiripan terendah yaitu pada daerah pertemuan pembuangan limbah industri. Kelimpahan fitoplankton termasuk dalam kategori kelimpahan yang sedang, indeks keanekaragaman dan indeks keseragaman fitoplankton rendah. Berdasarkan kandungan klorofil-a dan nitrat perairan Sungai Morosari termasuk ke dalam perairan oligotrofik, sedangkan berdasarkan kandungan fosfat termasuk ke dalam perairan mesotrofik dan eutrofik.
\end{abstract}

Kata Kunci : Klorofil-a; Nitrat; Fosfat; Fitoplankton; Sungai Morosari

\section{ABSTRACT}

Morosari river located in District Sayung, Demak is used for the disposal of domestic and industrial waste, traffic, fishing boats, tourist areas and fisheries activities. And may affect the water quality. The study was conducted in April-May 2014, aimed to determine the condition of the river by chlorophyll-a, nitrate, phosphate, and phytoplankton community structure at different locations. Other variables included temperature, currents, depth, transparency, $\mathrm{pH}$, salinity, and dissolved oxygen. This study used four stations with three replications. Analysis of the data used cluster analysis and the Kruskal-Wallis non parametric analysis. The results showed a significant difference in the content of chlorophyll-a and phosphate each station, while the nitrate content there was no significant difference. The highest similarity based on the phytoplankton community was between residential areas and traffic areas fishing boat, while the lowest is similarity was in industrial waste disposal area. The abundance of phytoplankton included in the category of moderate abundance, phytoplankton diversity and evenness index were low. Based on the content of chlorophyll-a and nitrate Morosari river waters belong to the oligotrophic waters, while based on the phosphorus content included into the mesotrophic waters.

Keywords : Chlorophyll-a; Nitrate; Phosphate; Phytoplankton; Morosari River

\section{PENDAHULUAN}

Sungai Morosari merupakan sungai yang berada di Kecamatan Sayung, Kabupaten Demak. Perairan Sungai Morosari ini dimanfaatkan untuk berbagai macam aktivitas penduduk seperti pembuangan limbah domestik maupun industri, jalur lalu lintas perahu nelayan, kawasan wisata, dan kegiatan perikanan (budidaya dan tangkap). Kegiatan-kegiatan tersebut diduga sangat berpotensi mengganggu kandungan klorofil-a, nitrat, fosfat, dan struktur komunitas fitoplankton di perairan Sungai Morosari.

Masukan kandungan nutrien yang berasal dari daratan melalui aliran sungai mempengaruhi kondisi perairan sungai dalam badan air, nutrien tersebut khususnya adalah dalam bentuk nitrat dan fosfat. Nutrien merupakan zat-zat yang diperlukan dan mempunyai pengaruh besar terhadap proses dan perkembangan hidup organisme seperti fitoplankton. Kedua zat hara ini berperan penting dalam proses fotosintesis. Tinggi rendahnya

\footnotetext{
${ }^{\circ}$ Copyright by Management of Aquatic Resources (MAQUARES)
} 
kelimpahan fitoplankton di perairan pergantung pada kandungan zat hara tersebut, sehingga nitrat dan fosfat juga dapat mempengaruhi kandungan klorofil-a yang terkandung dalam fitoplankton.

Fitoplankton merupakan tumbuhan yang memiliki klorofil-a yang berfungsi mengubah sinar matahari menjadi energi kimia yang diperlukan untuk melakukan proses fotosintesis. Dalam mata rantai makanan (food chain) di perairan, fitoplankton mempunyai fungsi sebagai produsen primer dimana organisme ini mampu mengubah bahan anorganik menjadi bahan organik melalui proses fotosintesis, untuk itu maka kandungan klorofil-a digunakan sebagai standing stock fitoplankton yang dapat dijadikan produktivitas primer suatu perairan. Jumlah klorofil-a pada setiap individu fitoplankton tergantung pada jenis fitoplankton, oleh karena itu komposisi jenis fitoplankton sangat berpengaruh terhadap kandungan klorofil-a di perairan.

Tujuan utama dari penelitian ini untuk mengetahui kondisi perairan Sungai Morosari pada lokasi yang berbeda berdasarkan kandungan klorofil-a, nitrat, fosfat, dan struktur komunitas fitoplankton.

Tujuan antara dari penelitian ini adalah:

1. Mengetahui kandungan klorofil-a, nitrat, dan fosfat pada lokasi yang berbeda di perairan Sungai Morosari; dan

2. Mengetahui struktur komunitas fitoplankton pada lokasi yang berbeda di perairan Sungai Morosari.

\section{MATERI DAN METODE PENELITIAN}

Penelitian ini dilakukan di perairan Sungai Morosari, Kecamatan Sayung, Kabupaten Demak. Stasiun 1 merupakan bagian sungai yang merupakan daerah pertemuan pembuangan limbah industri. Pada stasiun 2 merupakan daerah yang didominasi oleh pemukiman penduduk. Pada stasiun 3 merupakan daerah lalu lintas perahu dan tempat sandar perahu nelayan. Pada stasiun 4 berada pada muara sungai, pada daerah ini terdapat banyak mangrove dan merupakan kawasan wisata. Koordinat lokasi penelitiandapat dilihat pada Tabel 1.

Tabel 1. Koordinat Lokasi Penelitian

\begin{tabular}{ccc}
\hline No. & \multicolumn{2}{c}{ Koordinat } \\
\hline Stasiun 1 & $\mathrm{S}=6^{\circ} 56^{\prime} 31.60^{\prime \prime} \mathrm{S}$ & $\mathrm{E}=110^{\circ} 30^{\prime} 22.00^{\prime \prime} \mathrm{T}$ \\
Stasiun 2 & $\mathrm{S}=6^{\circ} 56^{\prime} 10.60^{\prime \prime} \mathrm{S}$ & $\mathrm{E}=110^{\circ} 29^{\prime} 56.30^{\prime \prime} \mathrm{T}$ \\
Stasiun 3 & $\mathrm{S}=6^{\circ} 55^{\prime} 47.90^{\prime \prime} \mathrm{S}$ & $\mathrm{E}=110^{\circ} 29^{\prime} 20.60^{\prime \prime} \mathrm{T}$ \\
Stasiun 4 & $\mathrm{S}=6^{\circ} 55^{\prime} 28.71^{\prime \prime} \mathrm{S}$ & $\mathrm{E}=110^{\circ} 28^{\prime} 47.88^{\prime \prime} \mathrm{T}$ \\
\hline
\end{tabular}

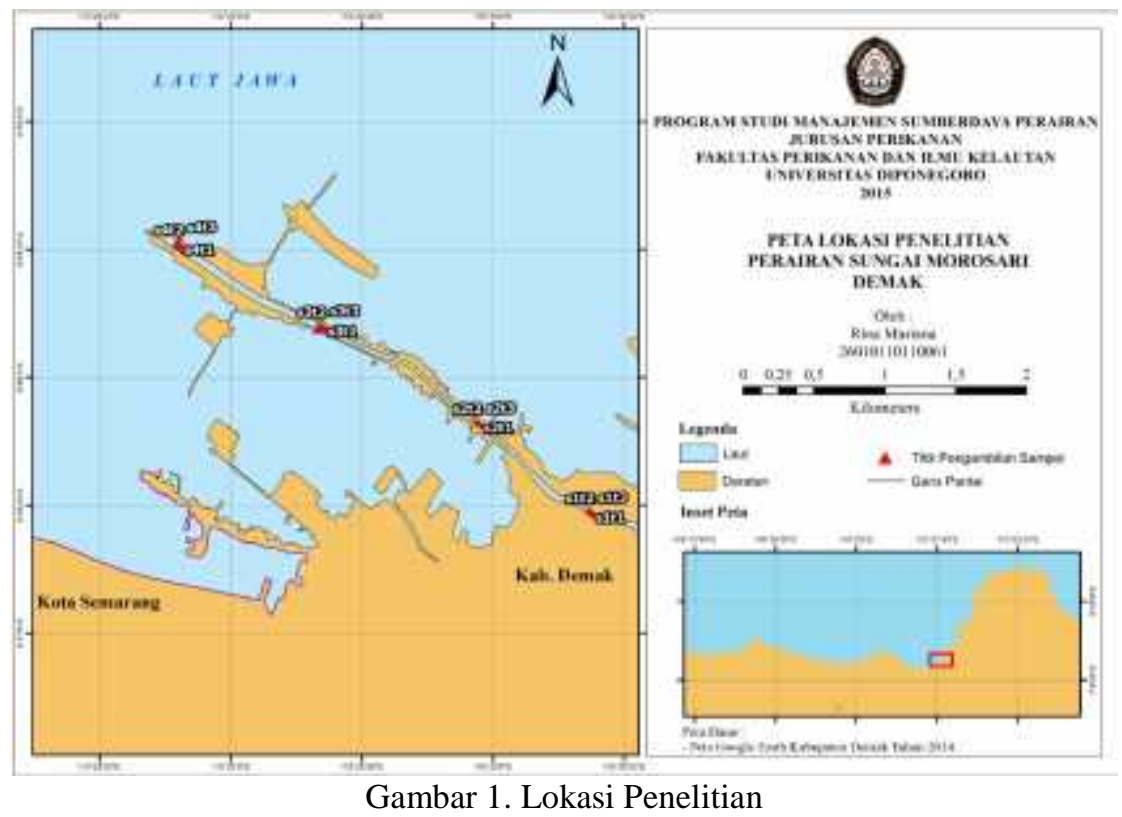

Variabel utama terdiri klorofil-a, nitrat, fosfat, dan struktur komunitas fitoplankton. Variabel pendukung yang juga dicatat antara lain temperatur, arus, kedalaman, kecerahan, pH, salinitas, dan oksigen terlarut. Metode untuk mengukur variabel tersebut adalah sebagai berikut.

\section{Pengukuran klorofil-a}

Sampel air diambil pada permukaan perairan dengan menggunakan botol 1,5 liter. Sampel air diambil sebanyak $1000 \mathrm{ml}$, disaring dengan kertas saring Whatman GF/C. Kertas saring kemudian digulung untuk dimasukkan ke dalam botol reagen kaca yang berisi $10 \mathrm{ml}$ larutan aseton $\left(\mathrm{CH}_{3} \mathrm{COCH}_{3}\right) 90 \%$ untuk mengekstrak sampel klorofil-a. Botol sampel disimpan dalam kondisi gelap dan pada suhu 40C selama 12-14 jam. Apabila 
supernatan masih keruh setelah dilakukan ekstraksi, maka diputar dengan centrifuge dengan kecepatan $5300 \mathrm{rpm}$ selama $2 \times 5$ menit, sehingga supernatan menjadi jernih dan endapannya terkumpul di dasar.

Konsentrasi klorofil-a ditetapkan dengan mengukur absorbansi pada panjang gelombang 664, 647 dan $630 \mathrm{~nm}$. Penyerapan pada panjang gelombang 664, 647dan $630 \mathrm{~nm}$ dikurangi dengan penyerapan pada panjang gelombang 750 untuk koreksi terhadap kekeruhan. Analisis konsentrasi klorofil-a dilakukan dengan mengikuti metode Radojevic dan Bashkin (1999).

Kadar klorofil yang telah diekstrak dapat dihitung dengan rumus Parsons et al., (1984) :

\section{Chl.-a = 11,85 E664 - 1,54 E647 - 0,08 E630 $\mu \mathrm{g} / \mathrm{ml}$}

E adalah absorbansi pada panjang gelombang yang berbeda (yang dikoreksi de-ngan panjang gelombang 750 $\mathrm{nm})$. Pada perhitungan kadar klorofil pada sampel maka angka di atas dikalikan dengan faktor (k) :

$$
\mathbf{k}=\frac{\mathbf{V a}}{\mathbf{V s \mathbf { x }} \mathbf{d}}
$$

Keterangan:

$\mathrm{Va}=$ volume aseton $(\mathrm{ml})$

Vs = volume sampel air yang disaring $(\mathrm{ml})$

$\mathrm{d}=$ volume kuvet

\section{Pengukuran nitrat}

Sampel air diambil pada permukaan perairan dengan menggunakan botol $600 \mathrm{ml}$. Analisis kandungan nitrat dalam air menggunakan Hach Programme dari spektrofotometer, spektrofotometer Hach pada $\lambda 355 \mathrm{~nm}$. Analisis konsentrasi nitrat dilakukan dengan metode SNI 06-2480-1991.

\section{Pengukuran fosfat}

Sampel air diambil pada permukaan perairan dengan menggunakan botol $600 \mathrm{ml}$. Analisis kandungan fosfat dalam air menggunakan Hach Programe dari spektrofotometer, spektrofotometer Hach pada $\lambda 490 \mathrm{~nm}$. Analisis konsentrasi fosfat dilakukan dengan mengikuti metode SNI 06-6989.31-2005.

\section{Kelimpahan fitoplankton}

Perhitungan kelimpahan fitoplankton per liter menggunakan rumus APHA (2005) yaitu:

Keterangan:

$$
\mathrm{N}=(\mathrm{T} / \mathrm{L}) \times(\mathrm{P} / \mathrm{p}) \times(\mathrm{V} / \mathrm{v}) \times(\mathbf{1} / \mathrm{W})
$$

$\mathrm{N}=$ Kelimpahan plankton (sel/l)

$\mathrm{T}=$ Luas total petak Sedgwick-Rafter $\left(1000 \mathrm{~mm}^{2}\right)$

$\mathrm{L}=$ Luas lapang pandang mikroskop $\left(\mathrm{mm}^{2}\right)$

$\mathrm{P}=$ Jumlah plankton yang tercacah (sel)

$\mathrm{P}=$ Jumlah lapang pandang yang diamati

$\mathrm{V}=$ Volume sampel plankton yang tersaring $(\mathrm{ml})$

$\mathrm{v}=$ Volume sampel plankton dalam Sedgwick-Rafter $(\mathrm{ml})$

$\mathrm{W}=$ Volume sampel air yang disaring (liter)

\section{Indeks keanekaragaman}

Keanekaragaman fitoplankton diketahui dengan menggunakan Indeks Keanekaragaman Shanon-Wiener (Mason, 1981) yang dirumuskan sebagai berikut:

$$
\mathbf{H}^{\prime}=-\sum_{\mathrm{I}=1}^{\mathrm{n}} \text { pi } \ln \mathrm{pi}
$$

Keterangan:

$\mathrm{H}^{\prime}=$ Indeks keanaekaragaman Shanon-Wiener

$\mathrm{pi}=\mathrm{ni} / \mathrm{N}$

$\mathrm{ni}=$ Jumlah individu jenis ke-1

$\mathrm{N}=$ Jumlah total individu

\section{Indeks keseragaman}

Indeks keseragaman digunakan untuk menunjukkan sebaran fitoplankton dalam suatu komunitas. Indeks kemerataan berdasarkan persamaan (Odum 1971):

$$
\mathrm{e}=\mathbf{H}^{\prime} / \mathrm{H} \text { maks }
$$

Keterangan:

H' = Indeks Keanekaragaman

$\mathrm{H}$ maks $=\ln \mathrm{S}$ (S adalah jumlah genus yang ditemukan)

e $\quad=$ Indeks keseragaman 
Indeks dominasi

Indeks dominasi diperoleh menggunakan indeks Simpson (Odum 1971), dengan persamaan:

Keterangan:

$$
\mathbf{D}=\sum[\mathbf{n i} / \mathbf{N}]^{2}
$$

$\mathrm{D}=$ Indeks dominasi Simpson

$\mathrm{ni}=$ Jumlah individu jenis ke- $\mathrm{i}$

$\mathrm{N}=$ Jumlah total individu

\section{Analisis Data}

Analisis kelompok (Cluster Analysis)

Analisis data yang digunakan untuk mengetahui pengelompokan stasiun berdasarkan komunitas fitoplankton dan variabel fisika kimia menggunakan analisis kelompok. Data yang berada dalam kelompok yang sama mempunyai sifat yang relatif homogen berdasarkan persamaan dari Bray-Curtis (Sugianto,1994). Proses pengolahan data dibantu dengan menggunakan software PAST Ver.3.

Analisis kelompok adalah teknik pengelompokan (klasifikasi) untuk menempatkan entitas atau obyek yang sama ke dalam kelompok-kelompok (grup). Grup-grup yang terbentuk memiliki homogenitas internal yang tinggi dan heterogenitas eksternal yang tinggi. Model yang digunakan adalah menempatkan obyek dalam suatu kelompok yang disusun secara hirarki membentuk struktur pohon (dendogram), (Sugianto,1994).

\section{Analisis Kruskal-Wallis}

Analisis Kruskal-Wallis adalah uji nonparametrik yang digunakan untuk membandingkan tiga atau lebih kelompok data sampel. Analisis Kruskal-Wallis digunakan karena asumsi distribusi dari masing-masing kelompok secara normal tidak terpenuhi (Sulaiman, 2003; Sugiyono, 2004). Untuk mengetahui perbedaan kandungan klorofil-a, nitrat, dan fosfat tiap stasiun menggunakan analisis nonparametrik Kruskal-Wallis dengan batas kemaknaan $\mathrm{p}<0,05$. Uji Kruskal-Wallis dibantu dengan menggunakan software PAST Ver.3

\section{HASIL DAN PEMBAHASAN}

\section{Hasil}

Kandungan Klorofil-a, Nitrat, dan Fosfat

Berdasarkan hasil analisis laboratorium nilai kandungan klorofil-a, nitrat dan fosfat di perairan Sungai Morosari dapat dilihat pada Tabel 2 .

Tabel 2. Hasil pengukuran kandungan klorofil-a, nitrat, dan fosfat (mg/l)

\begin{tabular}{ccccccc}
\hline \multirow{2}{*}{ Stasiun } & \multicolumn{2}{c}{ Klorofil-a } & \multicolumn{2}{c}{ Nitrat } & \multicolumn{2}{c}{ Fosfat } \\
\cline { 2 - 7 } & Kisaran & Rata-rata \pm SD & Kisaran & Rata-rata \pm SD & Kisaran & Rata-rata \pm SD \\
\hline Stasiun 1 & $0,044-0,246$ & $0,118 \pm 0,110$ & $0,5-1,0$ & $0,8 \pm 0,26$ & $0,13-0,46$ & $0,31 \pm 0,16$ \\
Stasiun 2 & $0,034-0,136$ & $0,075 \pm 0,053$ & $0,2-0,7$ & $0,5 \pm 0,26$ & $0,15-0,97$ & $0,46 \pm 0,44$ \\
Stasiun 3 & $0,044-0,212$ & $0,100 \pm 0,096$ & $0,4-1,3$ & $0,7 \pm 0,49$ & $0,24-0,82$ & $0,49 \pm 0,29$ \\
Stasiun 4 & $0,022-0,192$ & $0,082 \pm 0,094$ & $0,5-1,1$ & $0,8 \pm 0,32$ & $0,16-0,45$ & $0,27 \pm 0,15$ \\
\hline
\end{tabular}

Hasil analisis data klorofil-a mengunakan analisis Kruskal Wallis diperoleh nilai $p=0,02416(p<0,05)$, sehingga terdapat perbedaan yang nyata pada kandungan klorofil-a.

Hasil analisis data nitrat mengunakan analisis Kruskal Wallis diperoleh nilai $\mathrm{p}=0,6221(\mathrm{p}>0,05)$, sehingga tidak terdapat perbedaan yang nyata pada kandungan nitrat.

Hasil analisis data fosfat mengunakan analisis Kruskal Wallis diperoleh nilai $\mathrm{p}=0,00971(\mathrm{p}<0,05)$, sehingga terdapat perbedaan yang nyata pada kandungan fosfat.

\section{Struktur Komunitas Fitoplankton}

Fitoplankton yang didapatkan selama penelitian di perairan Sungai Morosari terdiri dari 5 kelas dan 32 spesies, yaitu kelas Chlorophyceae (12 spesies), kelas Euglenophyceae (1 spesies), kelas Cyanophyceae (4 spesies), kelas Dinophyceae (2 spesies), dan kelas Bacillariophyceae (13 spesies).

Hasil perhitungan indeks keanekaragaman, indeks keseragaman, indeks dominasi, dan kelimpahan yang didapatkan selama penelitian di perairan Sungai Morosari Demak tersaji dalam Tabel 3.

Tabel 3. Indeks Keanekaragaman, Indeks Keseragaman, Indeks Dominasi, dan Kelimpahan Fitoplankton di Perairan Sungai Morosari

\begin{tabular}{ccccc}
\hline Struktur Komunitas & Stasiun 1 & Stasiun 2 & Stasiun 3 & Stasiun 4 \\
\hline N (Kelimpahan) & 2317 & 1132 & 1132 & 1878 \\
H' (Indeks Keanekaragaman) & 2,10 & 2,05 & 2,25 & 2,01 \\
e (Indeks Keseragaman) & 0,39 & 0,55 & 0,43 & 0,39 \\
d (Indeks Dominasi) & 0,79 & 0,82 & 0,83 & 0,79 \\
\hline
\end{tabular}




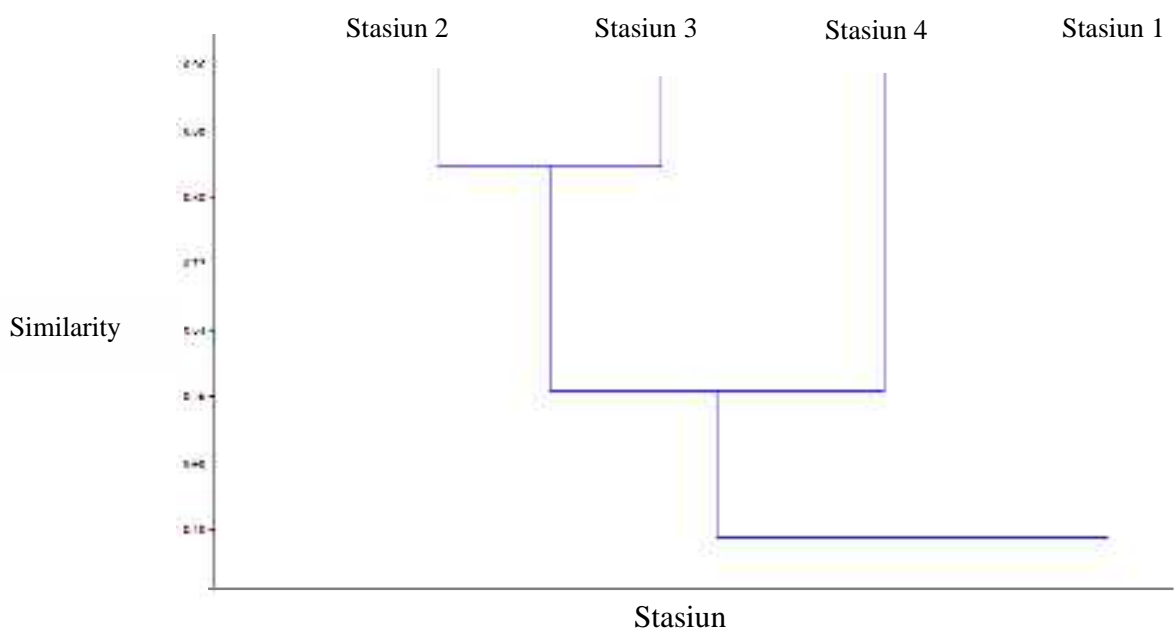

Gambar 2. Grafik Dendogram Berdasarkan Komunitas Fitoplankton Tiap Stasiun

Berdasarkan pengolahan data yang telah dilakukan menunjukkan 3 kluster yang terbentuk. Pada tahap pertama Stasiun 2 digabungkan dengan Stasiun 3 dengan nilai similaritas $84 \%$, yang artinya kedua stasiun tersebut memiliki kemiripan yang tinggi sebesar $84 \%$. Tahap kedua Stasiun 2 digabungkan dengan Stasiun 4 dengan nilai similaritas $56 \%$, yang artinya kedua stasiun tersebut memiliki kemiripan yang sedang sebesar 56 $\%$. Tahap ketiga Stasiun 2 digabungkan dengan Stasiun 1 dengan nilai similaritas 39\%, yang artinya kedua stasiun tersebut tidak terlalu mirip dengan nilai kemiripan $39 \%$.

\section{Variabel Pendukung (Variabel Fisika dan Kimia)}

Secara umum data variabel pendukung karakteristik perairan Sungai Morosari terbagi pada variabel fisika dan kimia. Adapun nilai rata-rata variabel fisika kimia dapat dilihat pada Tabel 4.

Tabel 4. Nilai Rata-rata Variabel Fisika dan Kimia Perairan Sungai Morosari

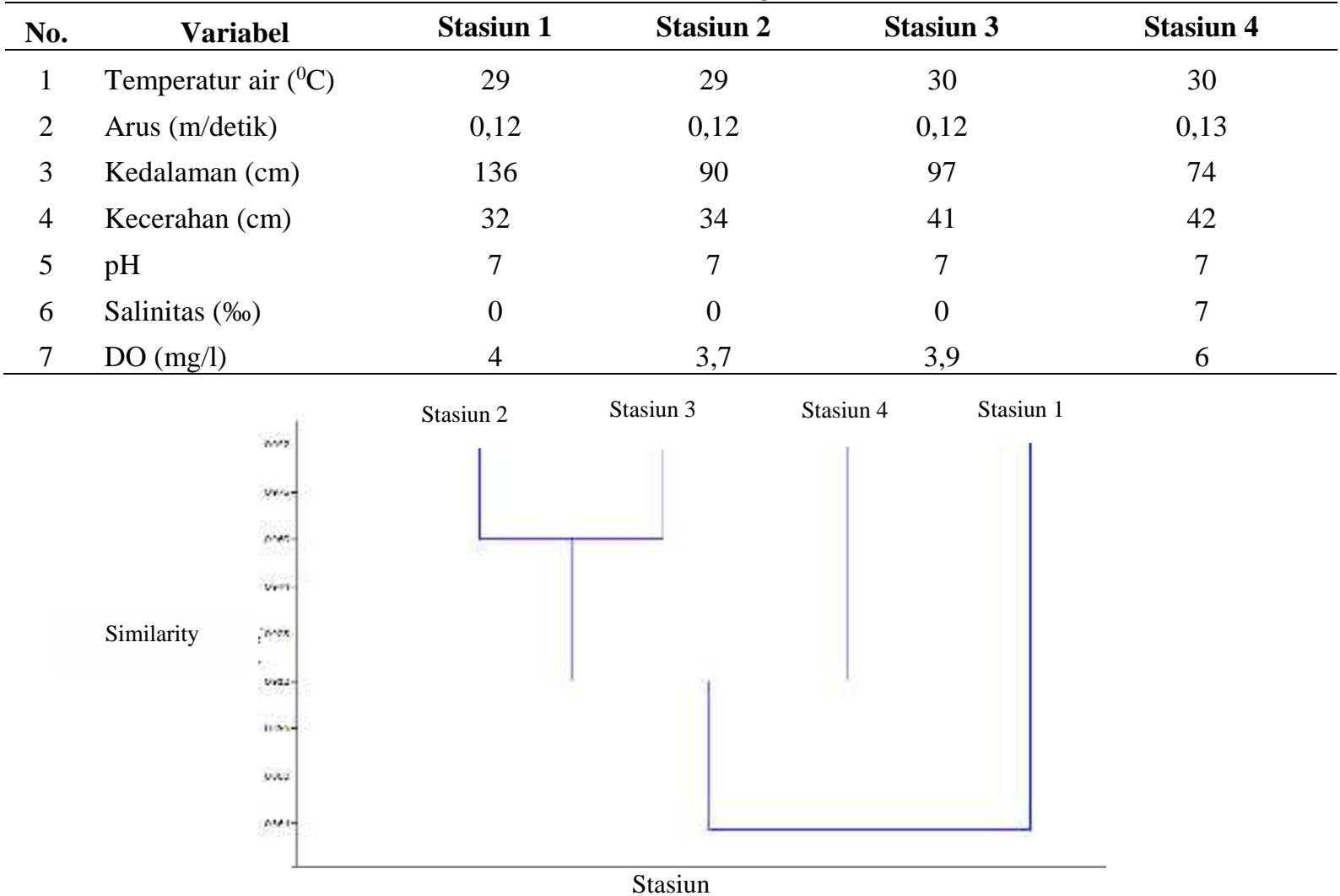

Gambar 3. Grafik Dendogram Berdasarkan Variabel Fisika dan Kimia Tiap Stasiun 
Berdasarkan pengolahan data yang telah dilakukan menunjukkan 3 kluster yang terbentuk. Pada tahap pertama Stasiun 2 digabungkan dengan Stasiun 3 dengan nilai similaritas $96 \%$, tahap kedua Stasiun 2 digabungkan dengan Stasiun 4 dengan nilai similaritas 91,2 \%, tahap kedua Stasiun 2 digabungkan dengan Stasiun 1 dengan nilai similaritas $86,4 \%$. Jika dilihat dari posisi stasiun pengamatan pengelompokan stasiunstasiun ini memiliki kemiripan yang relatif tinggi karena posisi stasiun yang masih berdekatan dengan karakteristik fisik kimia yang hampir sama.

\section{Pembahasan \\ Variabel utama(klorofil-a, nitrat, fosfat, dan struktur komunitas fitoplankton)}

Hasil pengukuran nilai klorofil-a berkisar antara 0,022-0,246 mg/l. Kandungan klorofil-a pada tiap stasiun berbeda nyata. Nilai kandungan klorofil-a di stasiun IV paling rendah karena berlokasi di muara sungai, hal ini diduga kerena kurangnya masukan nutrien dari daratan. Hal ini sesuai penelitian Sihombing (2013), kandungan klorofil-a terendah yaitu pada stasiun 10, karena letak stasiun10 sudah menuju ke arah laut lepas sehingga mengakibatkan sedikitnya masukan nutrien dari daratan yang menyebabkan kandungan klorofilnya lebih sedikit. Tinggi rendahnya kandungan klorofil sangat erat hubungannya dengan pasokan nutrien yang berasal dari darat melalui aliran sungai-sungai yang bermuara ke perairan tersebut. Menurut Parslow et al., (2008), berdasarkan nilai rata-rata klorofil-a yang diperoleh perairan Sungai Morosari tergolong kedalam perairan yang bersifat oligotrofik atau tingkat kesuburanya rendah.

Hasil pengukuran nilai nitrat berkisar antara 0,2-1,3mg/l. Kandungan nitrat di perairan Sungai Morosari menunjukkan hasil tidak berbeda nyata pada tiap stasiun penelitian dengan hasil nilai nitrat yang hampir sama. Kandungan nitrat di perairan Sungai Morosari masih berada pada kisaran kebutuhan bagi berlangsungnya produksi fitoplankton, seperti yang dikemukakan oleh Mackenthum (1969) dalam Andriani (2004), bahwa bila kandungan nitrat lebih dari $0,1 \mathrm{mg} / \mathrm{l}$ masih dapat digunakan untuk pertumbuhan fitoplankton sedangkan apabila kurang dari $0,1 \mathrm{mg} / \mathrm{l}$ merupakan faktor pembatas di perairan tersebut. Kandungan nitrat yang didapatkan selama penelitian menunjukkan perairan Sungai Morosari termasuk ke dalam kategori perairan oligotropik atau tingkat kesuburanya rendah.

Hasil pengukuran nilai fosfat berkisar antara 0,13-0,97 mg/l. Berdasarkan nilai rata-rata fosfat yang diperoleh perairan Sungai Morosari tergolong kedalam perairan yang bersifat mesotrofik dan eutrofik. Tinggi rendahnya kadar fosfat pada perairan sungai diduga karena adanya pengaruh dari buangan limbah industri dan limbah domestik dari lingkungan sekitar sungai. Terdapat perbedaan yang nyata pada kandungan fosfat tiap stasiun penelitian. Kadar fosfat di perairan Sungai Morosari termasuk dalam kategori sangat baik sekali. Hal ini sesuai dalam pendapat Joshimura (1966) dalam Hartoko (2010), kadar fosfat 0,201 mg/l atau lebih menunjukkan bahwa tingkat kesuburannya sangat baik sekali. Tingginya kadar fosfat pada ekosistem sungai diduga akibat dari kegiatan industri dan rumah tangga yang membuang limbah ke daerah sekitar sungai. Menurut Wattayakorn (1988), kandungan fosfat dan nitrat di daerah estuari selain berasal dari perairan itu sendiri juga tergantung kepada keadaan sekelilingnya.

Kelimpahan fitoplankton pada stasiun I yaitu 2317 ind/l, stasiun II yaitu 1132 ind/l, stasiun III yaitu 1132 ind/l, dan stasiun IV yaitu 1878 ind/l. Kelimpahan tertinggi terdapat pada stasiun I, hal ini diduga bahwa kegiatan pada stasiun I yang merupakan daerah pembuangan limbah industri memberikan kontribusi bagi peningkatan konsentrasi bahan nutrisi dalam air yang menyebabkan pertumbuhan fitoplankton yang optimal. Kelimpahan fitoplankton di stasiun I lebih tinggi daripada stasiun lain diduga karena konsentrasi fosfat pada stasiun ini lebih rendah dibandingkan dengan stasiun lain. Hal serupa dikatakan oleh Effendi (2003) bahwa kenaikan jumlah sel fitoplankton atau diatom diiringi dengan penurunan kadar fosfat. Fosfor juga merupakan unsur esensial bagi tumbuhan tingkat tinggi dan alga sehingga unsur ini menjadi faktor pembatas bagi tumbuhan dan alga akuatik serta sangat mempengaruhi tingkat produktivitas perairan. Hasil penghitungan kelimpahan berkisar antara 1132 ind/l - 2317 ind/l yang artinya kelimpahan dengan kisaran tersebut termasuk dalam kategori kelimpahan yang sedang. Hal ini sesuai dengan Madinawati (2010), yang menyatakan bahwa kelimpahan dengan nilai $<1.000 \mathrm{ind} / 1$ termasuk rendah, kelimpahan antara 1.000-40.000 ind/l tergolong sedang, dan kelimpahan > $40.000 \mathrm{ind} / 1$ tergolong tinggi. Kelimpahan fitoplankton berdasarkan hasil perhitungan selama penelitian menunjukkan kelimpahan kelas Bacillariophyceae yang mendominasi pada setiap stasiun. Spesies yang paling mendominasi yaitu Nitzschia palea. Hal ini mungkin disebabkan karena kelas Bacillariophyceae mampu menyesuaikan diri dengan kondisi lingkungan sekitarnya dibandingkan dengan kelas lainnya. Hal ini sesuai dengan Arinardi et al., (1997), kelas Bacillariophyceae lebih mampu beradaptasi dengan kondisi lingkungan yang ada, kelas ini bersifat kosmopolitan serta mempunyai toleransi dan daya adaptasi yang tinggi. Menurut Nybakken (1992), jenis ini mampu tumbuh dengan cepat meskipun nutrien dan cahaya rendah. Selain itu fitoplankton dari kelas ini juga mampu meregenerasi dan reproduksi yang lebih besar, serta memiliki kemampuan untuk bereproduksi yang tinggi sehingga jumlahnya lebih mendominasi dibandingkan dengan genus yang lain.

Berdasarkan pengolahan data yang telah dilakukan menunjukkan 3 kelompok yang terbentuk berdasarkan komunitas fitoplankton pada masing-masing stasiun. Perbedaan nilai komunitas fitoplankton pada setiap stasiun diduga dipengaruhi oleh pergerakan massa air, kecepatan arus dan nutrien. Plankton hidup tersuspensi dalam air

\footnotetext{
Co Copyright by Management of Aquatic Resources (MAQUARES)
} 
dan dipengaruhi daya yang menggerakkan massa air disekitarnya. Kononen et al., dalam Madubun (2008), berpendapat bahwa faktor hidrodinamika adalah penting dalam membangun pengelompokan dan penyebaran fitoplankton. Hal ini terjadi karena adanya hubungan antara difusi horizontal massa air dengan laju pertumbuhan fitoplankton.

Nilai indeks keanekaragaman yang didapatkan pada stasiun I yaitu 2,10, stasiun II yaitu 2,05, stasiun III yaitu 2,25, dan stasiun IV yaitu 2,01. Berdasarkan hasil tersebut, indeks keanekaragaman fitoplankton di Sungai Morosari menunjukkan kisaran < 2,3026 yang berarti perairan tersebut memiliki keanekaragaman fitoplankton yang rendah. Hasil perhitungan indeks keseragaman di Sungai Morosari pada stasiun I yaitu 0,39, stasiun II yaitu 0,55 , stasiun III yaitu 0,43 , dan stasiun IV yaitu 0,39 . Nilai indeks keseragaman tersebut berkisar antara 0-0,5 menunjukkan kemerataan antar spesies rendah, artinya kerapatan individu yang dimiliki masingmasing spesies sangat jauh berbeda. Apabila keseragaman mendekati nol, berarti keseragaman antar spesies di dalam komunitas tergolong rendah dan sebaliknya keseragaman yang mendekati satu dapat dikatakan keseragaman antar spesies tergolong merata atau sama (Pirzan et al., 2005). Kondisi seimbang adalah jika nilai indeks keanekaragaman dan indeks keseragaman tinggi. Ketersediaan nutrisi dan pemanfaatan nutrisi yang berbeda menyebabkan nilai indeks keanekaragaman dan indeks keseragaman rendah (Sastrawijaya, 1991 dalam Yazwar, 2008). Nilai indeks dominasi (d) yang terdapat pada stasiun I yaitu 0,79, stasiun II yaitu 0,82, stasiun III yaitu 0,83 , dan stasiun IV yaitu 0,79 . Nilai indeks dominasi berkisar $>0,5$ menunjukkan terdapat spesies yang mendominasi spesies lainnya atau struktur komunitas labil, karena terjadi tekanan ekologis. Indeks keanekaragaman Shanon Wiener berhubungan dengan indeks dominasi Simpson dimana jika keanekaragaman tinggi maka dominasi juga tinggi, hal ini ditunjukkan pada stasiun 3 yaitu daerah tengah dekat dengan mara sungai dengan nilai indeks keanekaragaman dan dominasi tertinggi.

\section{Variabel Pendukung (Variabel Fisika dan Kimia)}

Temperatur perairan dilokasi penelitian berkisar antara $29-30^{\circ} \mathrm{C}$ dengan kondisi cuaca yang cerah. Suhu di perairan ini hampir merata. Nilai tersebut merupakan nilai yang normal bagi perkembangan plankton di perairan tropis yaitu $21-35^{\circ} \mathrm{C}$ (Wardoyo, 1983). Sedangkan menurut pendapat Yazwar (2008), bahwa suhu berpengaruh langsung terhadap perkembangan dan pertumbuhan fitoplankton dimana suhu yang optimal untuk pertumbuhan plankton $20-30^{\circ} \mathrm{C}$. Kecepatan arus di lokasi penelitian berkisar antara $0,12-0,13 \mathrm{~m} / \mathrm{detik}$, menurut Efendi (2003), sungai dicirikan oleh arus yang searah dan relatif kencang dengan kecepatan berkisar antara 0,1$1,0 \mathrm{~m} /$ detik. Kedalaman pada lokasi penelitian berkisar antara 74-136 cm, kecerahan perairan antara $32-42 \mathrm{~cm}$. Kedalaman dan kecerahan akan mempengaruhi penetrasi sinar matahari kedalam perairan. Tingginya kedalaman akan memperkecil pengaruh kekeruhan perairan sehingga cahaya dapat masuk ke perairan secara optimal dan dimanfaatkan dengan baik untuk pertumbuhan fitoplankton. Zat-zat terlarut dalam perairan mempengaruhi kecerahan yang berhubungan dengan penetrasi sinar matahari. Fluktuasi kekeruhan mengakibatkan nilai produktivitas primer juga sangat berfluktuatif. Pada kondisi yang ekstrim yakni perairan keruh dan kondisi mendung, dimana kecerahan hanya sampai belasan centimeter maka lapisan produktif hanya sekitar 30-40 cm (Hariyadi et al., 2007). Perairan Sungai Morosari termasuk pada tingkat kecerahan yang rendah dengan kecerahan 32-42 cm. Hal ini sesuai dengan pendapat Akrimi dan Gatot (2002), bahwa kecerahan air di bawah $100 \mathrm{~cm}$ tergolong tingkat kecerahan rendah.

Nilai derajat keasaman $(\mathrm{pH})$ pada lokasi penelitian yaitu 7. Derajat keasaman $(\mathrm{pH})$ sangat berpengaruh pada adaptasi organisme perairan, $\mathrm{pH}$ dipengaruhi oleh aktivitas fotosintesis, suhu dan terdapatnya ion. $\mathrm{Nilai} \mathrm{pH}$ pada lokasi penelitian masih dalam kisaran yang baik untuk kehidupan fitoplankton. Hal ini sesuai dengan pendapat Pescod (1973) dalam Asriyana dan Yuliana (2012), bahwa pH yang ideal untuk kehidupan fitoplankton di perairan adalah 6,5-8,0. Salinitas yang didapat selama penelitian berkisar antara 0-7\%o. Muara sungai Morosari mempunyai salinitas 7\%o, hal ini dipengaruhi oleh air laut sehingga akan mempengaruhi komposisi fitoplankton. Dapat dilihat kelimpahan individu tertinggi pada stasiun IV adalah Chaetoceros yang merupakan plankton jenis laut. Daerah estuaria merupakan daerah yang memiliki kadar salinitas rendah karena adanya sejumlah air tawar yang masuk yang berasal daratan serta disebabkan oleh adanya pasang surut. Kadar oksigen terlarut (DO) di perairan Sungai Morosari berkisar antara 3,7-6 mg/l. Standar baku mutu DO dalam Peraturan Pemerintah No. 82 tahun 2001 untuk air adalah >3,0 mg/l. Hal tersebut menandakan konsentrasi DO Perairan Sungai Morosari tersebut masih memenuhi standar baku mutu yang diperbolehkan.

\section{KESIMPULAN}

Kesimpulan yang diperoleh pada penelitian ini adalah sebagai berikut:

1. Kandungan klorofil-a dan fosfat di lokasi yang berbeda adalah berbeda nyata, sedangkan nitrat adalah tidak berbeda nyata.

2. Kesuburan perairan Sungai Morosari termasuk kedalam perairan oligotrofik berdasarkan kandungan klorofil-a dan nitrat, sedangkan berdasarkan kandungan fosfat termasuk kedalam perairan mesotrofik dan eurofik.

3. Berdasarkan hasil struktur komunitas fitoplankton di perairan Sungai Morosari, kelimpahan fitoplankton termasuk dalam kategori kelimpahan yang sedang, indeks keanekaragaman fitoplankton memiliki

C) Copyright by Management of Aquatic Resources (MAQUARES) 
keanekaragaman fitoplankton yang rendah, indeks keseragaman menunjukkan kemerataan antar spesies rendah, dan indeks dominasi menunjukkan terdapat spesies yang mendominasi spesies lainnya atau struktur komunitas labil.

4. Kemiripan tertinggi berdasarkan komunitas fitoplankton terletak pada daerah yang didominasi pemukiman penduduk dan daerah lalu lintas perahu nelayan, sedangkan kemiripan terendah yaitu pada daerah pertemuan pembuangan limbah industri.

\section{UCAPAN TERIMA KASIH}

Ucapan terima kasih ditujukan kepada Prof. Dr. Ir. Djoko Suprapto, DEA, Dr. Ir. Haeruddin, Msi., Dr. Ir. Pujiono W. Purnomo, MS., dan Churun Ain, SPi., MSi. yang telah banyak memberikan masukan kepada penulis dalam penulisan makalah ini.

\section{DAFTAR PUSTAKA}

Akrimi, dan Subroto, G. 2002. Teknik Pengamatan Kualitas Air dan Plankton di Reservat Danau Arang-Arang Jambi. Buletin Teknik Pertanian 7: 2-5. Balai Riset Perikanan Perairan Umum. Palembang.

American Public Health Association. 2005. Standard Methods for The Examination of Water and Wastewater, 21th edition. Washington: APHA, AWWA (American Waters Works Association) and WPCF (Water Pollution Control Federation), 42p.

Andriani. 2004. Analisis Hubungan Parameter Fisika-Kimia dan Klorofil-a dengan Produktivitas Primer Fitoplankton di Perairan Kabupaten Luwu. [Tesis]. Sekolah Pascasarjana Institut Pertanian Bogor, Bogor, $71 \mathrm{p}$.

Arinardi, O.H., Sutomo, A.B., Yusuf, S.A., Trimaningsih, Asnaryanti, E., Riyono, S.H. 1997. Kisaran Kelimpahan dan Komposisi Plankton Predominan di Perairan Kawasan Timur Indonesia. Pusat Penelitian dan Pengembangan Oseanologi Lembaga Ilmu Pengetahuan Indonesia. Jakarta.

Asriyana dan Yuliana. 2012. Produktivitas Perairan. Bumi Aksara. Jakarta. 278 hlm.

Effendi, H. 2003. Telaah Kualitas Air Bagi Pengelolaan Sumberdaya dan Lingkungan Perairan. Penerbit Kanisius, Yogyakarta, $258 \mathrm{hlm}$.

Hariyadi, S. E, Adiwilaga. T, Partono, Hardjomidjojo dan A. Damar. 2010. Produktivitas Primer Estuaria Sungai Cisadane Pada Musim Kemarau. Limnotek, 17(1): 59-57.

Hartoko, A. 2010. Oseanografi dan Sumberdaya Perikanan-Kelautan di Indonesia. Undip Press, Semarang, 466 hlm.

Madinawati. 2010. Kelimpahan dan Keanekaragaman Plankton di Perairan Laguna Desa Tolongano Kecamatan Banawa Selatan. Media Litbang Sulawesi Tengah. Media Litbang Sulteng, 3 (2): 119 - 123.

Madubun, U. 2008. Produktivitas Primer Fitoplankton dan Kaitannya dengan Unsur Hara dan Cahaya di Perairan Muara Jaya Teluk Jakarta. [TESIS]. Sekolah Pascasarjana. Institut Pertanian Bogor.

Mason, C. F. 1981. Biology of Fresh Water Pollution. Longman. Inc, New York, 250 p.

Nybakken, J. 1992. Biologi Laut. PT Gramedia Pustaka Raya, Jakarta, 459 hlm.

Odum, E. P. 1971. Fundamental of Ecology Third Edition. W. B. Saunders Company. London, 574p

Parslow, J., J. Hunter and A. Davidson. 2008. Estuarine Eutrophication Models. Final Report Project National River Health Program. Water Services Association of Melbourne Australia. CSIRO Marine Research. Hobart, Tasmania.

Parsons, T.R., M. Takeshi and B. Hagrave. 1984. Biological Oceanographic Processes. Third Edition. Oxford. Pergamon Press. Great Britain, 447 p

Peraturan Pemerintah RI No.82 tahun 2001 Tentang Pengelolaan Kualitas Air dan Pengendalian Pencemaran. Kementrian Lingkungan Hidup. Jakarta.

Pirzan, A. M. M, Utojo. M, Atmomarso. A, Tjaronge. Tangko dan Hasnawi. 2005. Potensi Lahan Budidaya Tambak dan Laut di Kabupaten Minahasa, Sulawesi Utara. Jurnal Penelitian Perikanan Indonesia. 11 (5):43-50.

Radojevic, M. and Bashkin, V.N. 1999. Practical Enviromental Analysis. Royal Society of Chemistry, Cambridge.

\footnotetext{
${ }^{\circledR}$ Copyright by Management of Aquatic Resources (MAQUARES)
} 
Sihombing, R.F., Aryawati, R., dan Maspari, H. 2013. Kandungan Klorofil-a Fitoplankton di Sekitar Perairan Desa Sungsang Kabupaten Banyuasin Provinsi Sumatera Selatan. Jurnal Perikanan, 5 (1), 34-39.

Sugianto, A. 1994. Ekologi Kuantitatif Metode Analisis Populasi dan Komunitas. Penerbit Usaha Nasional. Surabaya.

Sugiyono. 2004. Statistik Nonparametrik Untuk Penelitian. CV Alfabeta. Bandung. Sulaiman, W. 2003. Statistik Nonparametrik Contoh Kasus dan Pemecahannya dengan SPSS. Penerbit Andi. Yogyakarta,156 hlm.

Sulaiman, W. 2003. Statistik Nonparametrik Contoh Kasus dan Pemecahannya dengan SPSS. Penerbit Andi. Yogyakarta, $147 \mathrm{hlm}$.

Wardoyo, S. T. H. 1983. Metode Pengukuran Kualitas Air. Training. Penyusunan Analisis Mengenai Dampak Lingkungan. PUSDI-PSL Institut Pertanian Bogor. 60 p.

Wattayakorn, G. 1988. Nutrient Cyclingin Estuarine. Paper Presented in the Project on Research and its Application to Management of the Mangrove of Asia and Pasific, Ranong. Thailand, 17 pp.

Yazwar. 2008. Keanekaragam Plankton dan Keterkaitannya Dengan Kualitas Air di Parapat Danau Toba. [TESIS]. Sekolah Pascasarjana. Universitas Sumatera Utara. Medan. 21-77 hlm. 